ISSN 2073-4344

www.mdpi.com/journal/catalysts

Article

\title{
Downhole Upgrading of Orinoco Basin Extra-Heavy Crude Oil Using Hydrogen Donors under Steam Injection Conditions. Effect of the Presence of Iron Nanocatalysts
}

\section{Cesar Ovalles ${ }^{1, \dagger, *}$, Victor Rivero ${ }^{1}$ and Arelys Salazar ${ }^{2}$}

1 Center of Catalysis, Petroleum and Petrochemicals, Universidad Central de Venezuela, Caracas, 1042A, Venezuela; E-Mail: victor.rivero@nynas.com

2 Departamento de Quimica, Facultad de Ciencias y Tecnologia, Universidad de Carabobo, Valencia, 46003, Venezuela; E-Mail: asalaza@conocophillips.com

$\dagger$ Present address: Chevron Energy Technology Company, 100 Chevron Way, Suite 50-1279, Richmond, CA 94802, USA.

* Author to whom correspondence should be addressed; E-Mail: covalles@chevron.com; Tel.: +1-510-242-2991; Fax: +1-510-242-2807.

Academic Editor: Russell R. Chianelli

Received: 6 December 2014 / Accepted: 26 February 2015 / Published: 5 March 2015

\begin{abstract}
An extra-heavy crude oil underground upgrading concept and laboratory experiments are presented which involve the addition of a hydrogen donor (tetralin) to an Orinoco Basin extra-heavy crude oil under steam injection conditions $\left(280-315{ }^{\circ} \mathrm{C}\right.$ and residence times of at least 24-h). Three iron-containing nanocatalysts $(20 \mathrm{~nm}, 60 \mathrm{~nm}$ and $90 \mathrm{~nm}$ ) were used and the results showed increases of up to $8^{\circ}$ in API gravity, $26 \%$ desulfurization and $27 \%$ reduction in the asphaltene content of the upgraded product in comparison to the control reaction using inert sand. The iron nanocatalysts were characterized by SEM, XPS, EDAX, and Mössbauer spectroscopy before and after the upgrading reactions. The results indicated the presence of hematite $\left(\mathrm{Fe}_{2} \mathrm{O}_{3}\right)$ as the predominant iron phase. The data showed that the catalysts were deactivating by particle sintering ( $20 \%$ increase in particle size) and also by carbon deposition. Probable mechanisms of reactions are proposed.
\end{abstract}


Keywords: downhole; upgrading; extra-heavy crude oil; hydrogen donors; iron catalyst

\section{Introduction}

In general, downhole upgrading processes have several potential benefits in comparison to aboveround counterparts: Firstly, enhanced oil recovery can be obtained by accessing more difficult fluids with the potential increase of the volumetric production of wells. Secondly, decreases in the consumption of costly and scarce light and medium crude oils (used as diluents) can be achieved. Reductions in lifting and transportation costs of upgrading crude oil can also be attainable. Finally, there is the potential generation of higher value products with higher API gravities and reduced viscosity, asphaltene, sulfur and heavy-metal contents [1-6].

However, there are important technical challenges involved in developing subsurface upgrading processes. Firstly, downhole processes are difficult to monitor under reservoir conditions. Also, each well and reservoir requires individual treatment; thus, increasing the complexity of field operations [1-6].

In general, aquathermolysis is the thermal cracking of petroleum oils and hydrocarbons in the presence of water and has been studied for more than 30 years [7-11]. During steam-stimulated production of heavy oils, thermal energy breaks large molecules into smaller ones with the concomitant reduction of oil viscosity [7-11]. The aquathermolysis reaction can be accelerated in the presence of metal catalysts, and has become an important area of research over the last three years. Specifically, several research groups in Mexico [12,13], Japan [14] and China [15-19] have explored this route for the underground upgrading of heavy and extra heavy crude oils under conditions similar to those achieved under steam injection $\left(250-280^{\circ} \mathrm{C}\right)$. Some of the lab results have shown increases of up to $4-5^{\circ}$ API with two- to three-fold reduction of viscosity [12-15].

The catalytic aquathermolysis concept was field tested in the Liaohe Field, China in 2005 [16]. Twenty cyclic steam stimulation wells were treated by adding a dispersed catalyst formulation and hydrogen donors. Increases in the heavy oil production of the wells were obtained with high sulfur removal (86\%) and asphaltene removal (28\%) in comparison with the original crude oil.

In 2007, Wen et al. [16] reported additional field tests in the same oil field. Steam is injected into vertical wells to pre-heat the oil reservoir. A catalyst solution (Molybdenum Oleate) and the remainder of the steam are then injected into the reservoir (total of 12,500 BBL of steam) with a soak time of 7-10 days. Eight cyclic steam stimulation (CSS) wells were treated by this methodology and in seven wells increases in the heavy crude oil production were obtained [16].

Three metal derived catalysts (water soluble iron with tetralin, oil soluble molybdenum oleate and dispersed aromatic sulfonic iron) were compared and showed slightly higher activity in laboratory $v s$. field tests with differences in the 10-12\% range [15-17]. These results show that, indeed, the use of metal catalysts, with and without hydrogen donors has a synergic effect on viscosity reduction of heavy oils, hence the catalytic aquathermolysis and hydrogen addition could be used effectively for steam-stimulated oil recovery.

In 2012, Chen et al. [18] reported the use of an alkyl ester sulfonate copper (0.1-0.3 wt.\%), which has not only a catalytic center but also has a potential hydrogen precursor structure. In a field tests at 
Liaohe Field, steam was injected into a vertical well to pre-heat up the oil reservoir. The catalyst solution and the rest of the steam were then injected into the reservoir (total of 7500 BBL of steam, soaking time six days). Reductions of $85 \%$ viscosity and $54 \%$ asphaltene content were reported [18]. However, no description of the fate and recycling of the catalyst were reported as well as changes in the API gravity and sulfur contents.

In 2013, Chen et al. [19] studied the catalytic aquathermolysis of iron and copper based p-Toluenesulfonic catalysts for the upgrading of six heavy oils under lab conditions at $200{ }^{\circ} \mathrm{C}$ for $24 \mathrm{~h}$. As before, viscosity and asphaltene content reductions were reported. Using H-NMR, SEC and $\mathrm{GC}-\mathrm{MS}$, it was proposed that the $\mathrm{Cu}$ containing catalyst led to the de-polymerization and cleavage of some bridged bonds of the asphaltenes, whereas the iron counterpart mainly caused the ring-opening of heterocyclic rings and isomerization of side chains.

In our previous publications [3-6], we reported a concept that involves the addition of a hydrogen donor additive (tetralin or other distillate fractions having at least $40 \mathrm{wt} \%$ naphthenic aromatic compounds) and, in the presence of steam, natural formation (catalyst) and methane (natural gas), leads to extra-heavy crude oil upgrading (from 9 to $14^{\circ}$ API) at lab conditions [5,6]. This concept could be coupled to a steam stimulation process with $70-80 \%$ hydrogen donor recycled $[5,6]$. In our previous publication [5], X-ray photoelectron spectroscopy (XPS) analysis of the natural formation indicated the presence of 0.6 wt.\%. of iron as $\mathrm{Fe}_{2} \mathrm{O}_{3}$. The use of this compound as catalyst led to further reduction in the viscosity of the upgraded crude oil (from $5500 \mathrm{cP}$ at $60{ }^{\circ} \mathrm{C}$ with natural formation to $1300 \mathrm{cP}$ using $\mathrm{Fe}_{2} \mathrm{O}_{3}$ ) [5]. Thus, in this work, three iron-containing nanocatalysts were evaluated and laboratory experiments will be presented that involve the addition of a hydrogen donor additive (tetralin) to an Orinoco Basin extra-heavy crude oil (Hamaca C.) under steam injection conditions $\left(280-315^{\circ} \mathrm{C}\right.$ and residence times of at least $24-\mathrm{h}$.

\section{Results and Discussion}

\subsection{Upgrading Reaction}

The upgrading experiments were carried out under batch conditions with a sand:crude oil:tetralin:water ratio of 10:1:1:1 at $6.2 \mathrm{MPa}$ of $\mathrm{CH}_{4}$ of initial pressure at $280-315^{\circ} \mathrm{C}$ for $24 \mathrm{~h}$. Firstly, a control experiment (Table 1, Run 1 with $0 \mathrm{~h}$ ) was carried out in order to determine the effects of sample handling procedure. As can be seen, product characterization indicates an increase of only $1^{\circ}$ API, 5\% reduction of sulfur (\%HDS) and $9 \%$ reduction in asphaltenes. These changes can be attributed to upgrading reactions occurring during the time needed to reach the distillation temperature to separate the tetralin, which was approximately 30-45 $\min$ (see Experimental Section)

By increasing reaction time to $24 \mathrm{~h}$ (Table 1, Run 2), a product with higher ${ }^{\circ} \mathrm{API}\left(14.7^{\circ}\right)$ and lower percentages of sulfur (12\%) and asphaltenes (13\%) was obtained in comparison with the original crude oil. Even though the changes in the product properties were small and sometimes within the experimental error of the techniques used, the results presented in Table 1 indicates a general trend, which allows concluding that effective crude oil upgrading can be achieved in the presence of hydrogen donor (tetralin) at steam injection conditions $\left(315^{\circ} \mathrm{C}, 24 \mathrm{~h}\right)$ [5]. As mentioned, these results have been reported before in our previous publications [3-6]. 
The effect of the tetralin concentration (from $1 \%$ to $50 \% \mathrm{w} / \mathrm{w}$ ) on the properties of the upgraded crude oils was studied in our previous paper [5]. For example, the viscosity of the product decreased from 9870 to $2900 \mathrm{cP}$ (measured at $60^{\circ} \mathrm{C}$ ) with the hydrogen donor added up to $50 \% \mathrm{w} / \mathrm{w}$ [5].

Table 1. Properties of the upgraded crude oil using tetralin under steam injection conditions ${ }^{\text {a }}$. Effect of the presence of iron nanocatalysts.

\begin{tabular}{|c|c|c|c|c|}
\hline Run & Solid (Reaction time) & ${ }^{\circ} \mathrm{API}{ }^{\mathrm{b}}\left( \pm 0.5^{\circ}\right)$ & $\% \operatorname{HDS}^{\mathrm{c}}( \pm 1 \%)$ & $\%$ Asphaltenes Reduction ${ }^{d}$ \\
\hline- & Original Hamaca C. ${ }^{\mathrm{e}}$ & 9.1 & - & - \\
\hline 1 & Control Exp. $(0 \mathrm{~h})^{\mathrm{f}}$ & 10.2 & $5 \%$ & $9 \%$ \\
\hline 2 & Mineral Formation ${ }^{\mathrm{g}}$ & 14.7 & $12 \%$ & $13 \%$ \\
\hline 3 & $\mathrm{Fe}-20 / \mathrm{SiO}_{2}{ }^{\mathrm{h}}$ & 17.5 & $28 \%$ & $31 \%$ \\
\hline 4 & $\mathrm{Fe}-60 / \mathrm{SiO}_{2}{ }^{\mathrm{h}}$ & 14.5 & $22 \%$ & $19 \%$ \\
\hline 5 & $\mathrm{Fe}-90 / \mathrm{SiO}_{2}{ }^{\mathrm{h}}$ & 13.2 & $8.5 \%$ & $17.9 \%$ \\
\hline
\end{tabular}

${ }^{a}$ Experiments carried out under batch conditions, no stirring, Ratio sand:crude:tetralin:water $=10: 1: 1: 1,900$ psi of $\mathrm{CH}_{4}$ initial pressure, 1600 psi of final pressure at $315^{\circ} \mathrm{C}$ for $24 \mathrm{~h}$. Results are the average of at least two different experiments. ${ }^{b}$ API gravity. Numbers in bracket indicate the errors. ${ }^{c}$ Percentage of reduction of sulfur with respect to the original crude oil. Numbers in bracket indicate the errors. ${ }^{\mathrm{d}}$ Percentage of reduction asphaltenes with respect to the original crude oil. ${ }^{\mathrm{e}}$ Original crude oil before upgrading experiments. ${ }^{\mathrm{f}}$ Same experimental conditions, but the tetralin was removed and the products analyzed just as the reactor reached the operating temperature. ${ }^{\mathrm{g}}$ Natural mineral formation from the Hamaca reservoir. ${ }^{\mathrm{h}} 5$ wt.\%. (nominal) $\mathrm{Fe}$ supported on sand $\left(99 \% \mathrm{SiO}_{2}\right.$, partially dehydroxylated at $600{ }^{\circ} \mathrm{C}$ with a surface area of $\left.10 \mathrm{~m}^{2} / \mathrm{g}\right)$.

Next, three iron supported nanocatalysts were prepared by dispersion of commercial $20 \mathrm{~nm}, 60 \mathrm{~nm}$ and $90 \mathrm{~nm}$ iron oxide nanoparticles in a natural silica support (see Experimental Section for details). In the presence of iron-containing nanocatalysts, further improvement in the upgraded crude oil properties were obtained (Table 1, Runs 3-5). Maximum increases in the API gravity of up of $17.5^{\circ}$ API with percentage of hydrodesulfurization (\%HDS) of $28 \%$ and removal of asphaltenes of $31 \%$ were obtained (Run 3). These results clearly indicate that the presence of a catalyst is necessary to yield upgraded products with higher quality. Consistent with these and previous results, naphthalene was detected in the reaction media as determined by GC-MS analysis [3-6].

The fact that the removal of sulfur and asphaltenes increase in the presence of iron may indicate that the hydrogen transfer from the tetralin hydrogen donor could be assisted by the metal catalyst as reported in the literature [15-19] and by Sakanishi et al. during coal liquefaction experiments [20]. As reported previously [3-6], the main sulfur-containing product detected was $\mathrm{H}_{2} \mathrm{~S}$ in the gas formed (lower than $5 \% \mathrm{w} / \mathrm{w}$ ) during the upgrading experiments.

The effect of reaction temperature on the viscosity of the upgraded crude oils can be seen in Figure 1. As shown, the results indicate that the order of activity of the iron nanocatalysts is $\mathrm{Fe}-20 / \mathrm{SiO}_{2}>\mathrm{Fe}-60 / \mathrm{SiO}_{2}>\mathrm{Fe}-90 / \mathrm{SiO}_{2}$. It can be proposed that the order of activity is inversely proportional to the catalysts' initial particle size. Thus, different iron catalysts gave different upgraded crude oils with different properties. Therefore, the catalyst characterization study was carried out, and the results are presented in the next section. 


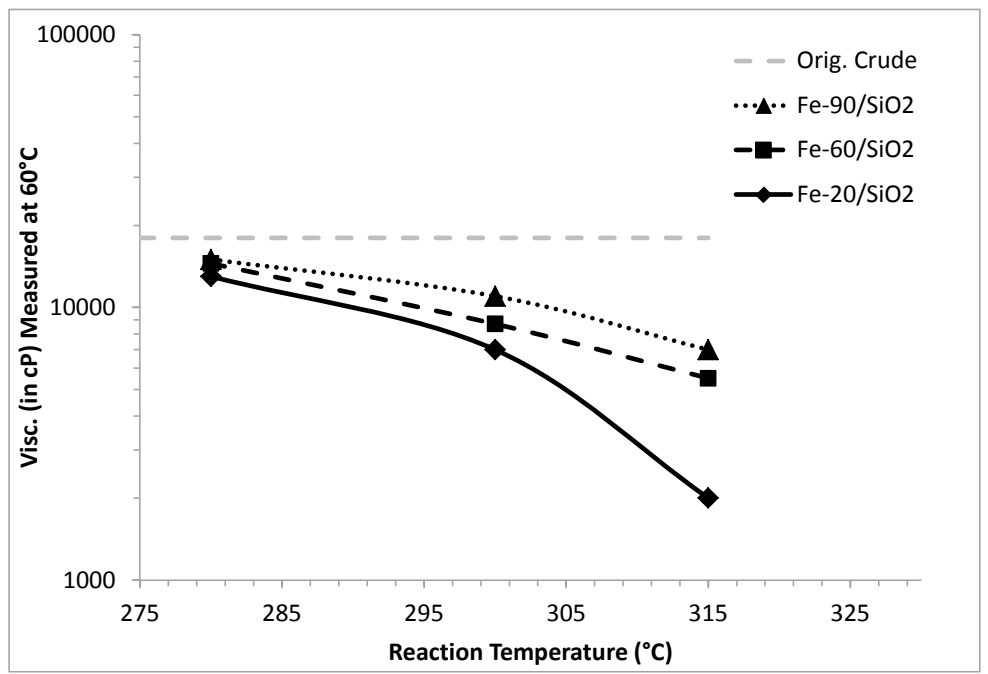

Figure 1. Viscosity (cP) at $60{ }^{\circ} \mathrm{C}$ of the upgraded crude oil using iron-containing catalysts.

\subsection{Catalyst Characterization}

Firstly, the catalysts were analyzed by Scanning Electron Microscopy (SEM) and the results are shown in Figure 2. As can be seen, the iron catalyst $\mathrm{Fe}-20 / \mathrm{SiO}_{2}$ before the upgrading reaction showed a more or less even dispersion with particles of similar size and shapes. The analysis of 100 particles gave a mean average size of $18 \mathrm{~nm}$. On the other hand, TEM analysis of the same catalyst after the upgrading reaction showed an uneven dispersion of the metal with particles of different shapes and sizes. The measurement of 100 particles gave a mean average size of $23 \mathrm{~nm}$ giving evidence of a particle sintering under reaction conditions $\left(315^{\circ} \mathrm{C}\right.$, tetralin, water, $\left.24 \mathrm{~h}\right)$.
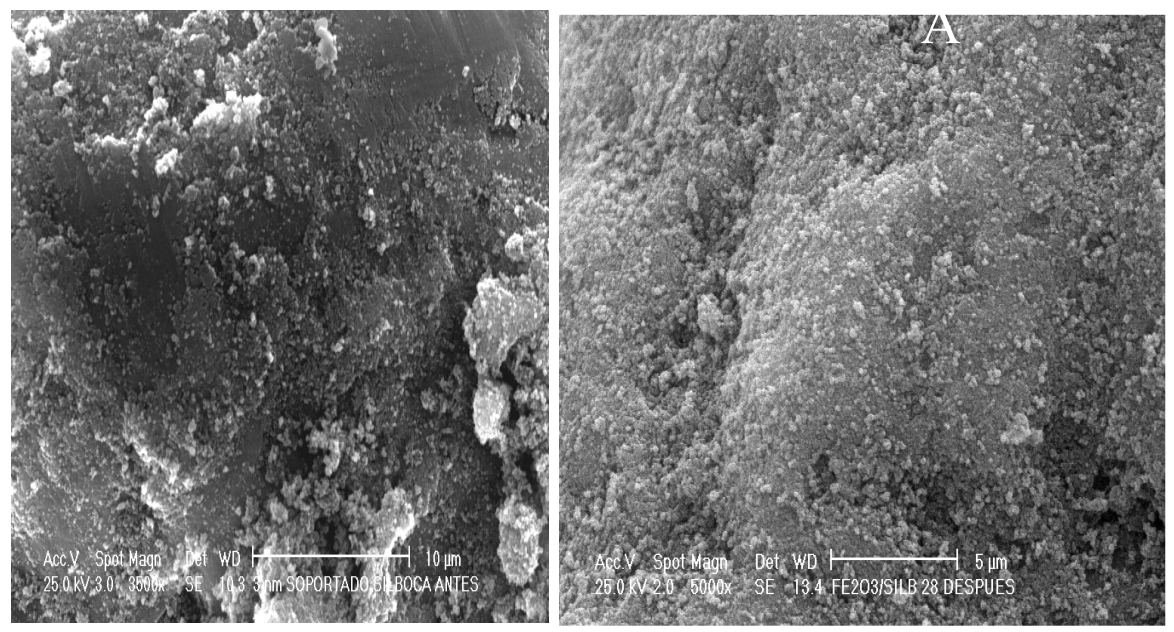

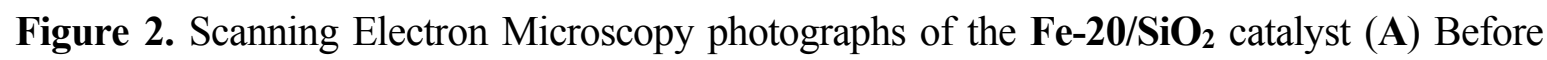
the upgrading reaction and (B) After the upgrading reaction $\left(315^{\circ} \mathrm{C}\right.$ and $24 \mathrm{~h}$, Tetralin).

The characterization of the $\mathrm{Fe}-60 / \mathrm{SiO}_{2}$ gave similar results with particles sizes of 53 and $61 \mathrm{~nm}$ before and after the upgrading reaction (See Figure 3). The differences in particle sizes and, presumably the metal dispersion, between $\mathrm{Fe}-20 / \mathrm{SiO}_{2}(18-23 \mathrm{~nm})$ and $\mathrm{Fe}-60 / \mathrm{SiO}_{2}(53-61 \mathrm{~nm})$ could explain why the first catalyst is more active (higher ${ }^{\circ} \mathrm{API}$, HDS and removal of asphaltenes) than the 
second (see Table 1). Similar results were obtained for $\mathrm{Fe}-90 / \mathrm{SiO}_{2}$ (from $83 \mathrm{~nm}$ to $93 \mathrm{~nm}$ before and after upgrading reaction).

The characterization by X-Ray Photoelectron Spectroscopy (XPS) of the iron catalyst $\mathrm{Fe}-20 / \mathrm{SiO}_{2}$ showed binding energies for the Fe $2 \mathrm{p} 3 / 2$ of 710.6 and $711.3 \mathrm{eV}$ before and after the upgrading experiments, respectively (Table 2). According to the data reported in the literature [21], these bands can be assigned to $\mathrm{Fe}^{3+}$ present in the $\mathrm{Fe}_{2} \mathrm{O}_{3}$. Consistent with these results, the $\mathrm{O} 1 \mathrm{~s}$ bands were found at 530.9 and $532.0 \mathrm{eV}$, respectively, and were assigned to $\mathrm{O}^{2-}$ [21]. Similar results were obtained for the $\mathrm{Fe}-60 / \mathrm{SiO}_{2}$ and $\mathrm{Fe}-90 / \mathrm{SiO}_{2}$ catalysts.
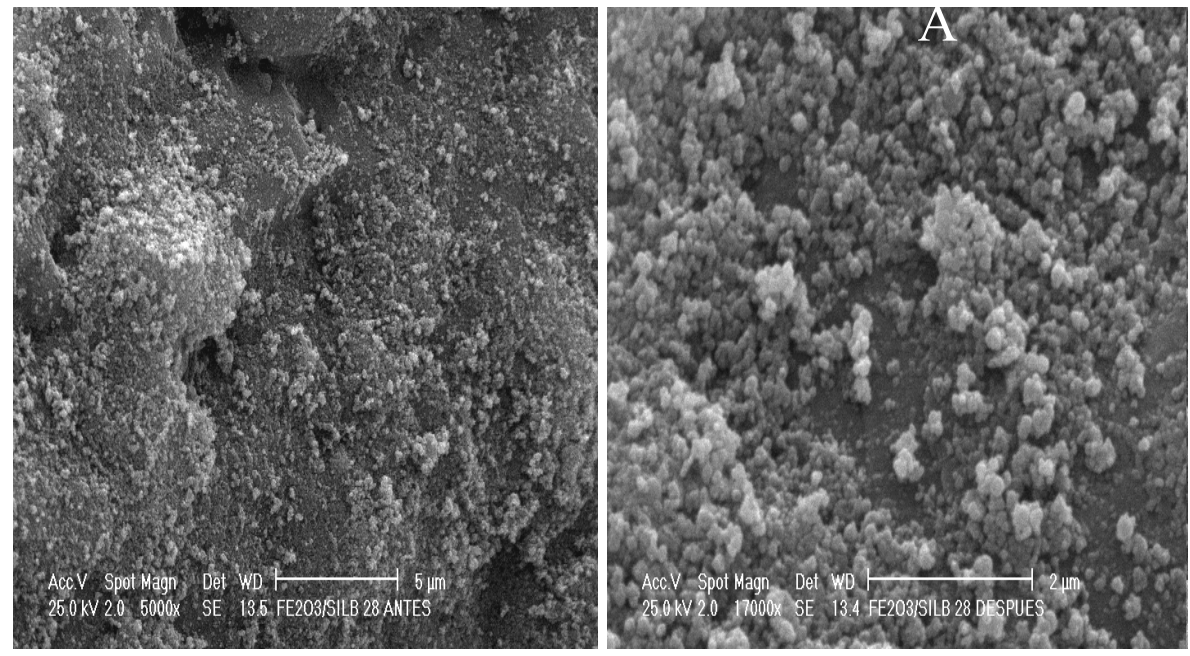

Figure 3. Scanning Electron Microscopy photographs of the $\mathbf{F e}-60 / \mathrm{SiO}_{2}$ catalyst (A) Before the upgrading reaction and (B) After the upgrading reaction $\left(315^{\circ} \mathrm{C}\right.$ and $24 \mathrm{~h}$, tetralin).

Table 2. Characterization by X-Ray Photoelectron Spectroscopy (XPS) of the iron catalyst $\mathrm{Fe}-20 / \mathrm{SiO}_{2}$.

\begin{tabular}{|c|c|c|c|c|}
\hline Experiment $^{\text {a }}$ & Element Band ${ }^{b}$ & Binding Energy $(e V)^{c}$ & $\%$ Atomic $^{d}$ & Fe-Dispersion ${ }^{\text {e }}$ \\
\hline \multirow{4}{*}{$\begin{array}{c}\text { Before } \\
\text { Upgrading } \\
\text { Reaction }\end{array}$} & $\mathrm{Fe} 2 \mathrm{p} 2 / 3$ & 710.6 & 16.27 & \multirow{4}{*}{4.54} \\
\hline & $\mathrm{O} 1 \mathrm{~s}$ & 530 & 25.07 & \\
\hline & $\mathrm{C} 1 \mathrm{~s}$ & 284.6 & 55.09 & \\
\hline & Si $2 p$ & 103.1 & 3.58 & \\
\hline \multirow{4}{*}{$\begin{array}{c}\text { After } \\
\text { Upgrading } \\
\text { Reaction }\end{array}$} & $\mathrm{Fe} 2 \mathrm{p} 2 / 3$ & 711.3 & 6.86 & \multirow{4}{*}{1.75} \\
\hline & $\mathrm{O} 1 \mathrm{~s}$ & 530.5 & 18.27 & \\
\hline & $\mathrm{C} 1 \mathrm{~s}$ & 284.6 & 69.18 & \\
\hline & Si $2 p$ & 103 & 5.68 & \\
\hline
\end{tabular}

${ }^{a}$ Experiments carried out under batch conditions, no stirring, Ratio sand:crude:tetralin:water $=8: 1: 1: 1,900$ psi of $\mathrm{CH}_{4}$ initial pressure, 1600 psi of final pressure at $315^{\circ} \mathrm{C}$ for $24 \mathrm{~h}$. ${ }^{\text {b }}$ Element analyzed and XPS band. ${ }^{\mathrm{c}}$ Binding energy in $\mathrm{eV} .{ }^{\mathrm{d}}$ Atomic percentage. ${ }^{\mathrm{e}}$ Iron dispersion calculated by dividing Iron atomic percentage into $\mathrm{Si}$ atomic percentage.

Also using the XPS data, iron dispersion was estimated by dividing the iron atomic percentage into the silicon atomic percentage. As can be seen in Table 2, Fe dispersion (as determined by Fe/Si atomic 
percentages) was reduced from 4.54 to 1.75 . These results are consistent with the increase in particle size determined by TEM. Similar results were obtained for the $\mathrm{Fe}-60 / \mathrm{SiO}_{2}$ and $\mathrm{Fe}-90 / \mathrm{SiO}_{2}$ catalysts.

The characterization of the $\mathrm{Fe}-20 / \mathrm{SiO}_{2}$ by XRD after the upgrading experiment can be seen in Figure 4. By using the XRD-library of the apparatus, $\mathrm{Fe}_{2} \mathrm{O}_{3}, \mathrm{SiO}_{2}$, coke, and graphite phases could be detected on the catalyst after the upgrading reactions. These results are consistent with those observed by XPS, in which iron, oxygen, silicon, and carbon were found on the catalyst surfaces.

To definitively determine the active phase on the surface, the $\mathrm{Fe}-20 / \mathrm{SiO}_{2}$ catalyst was analyzed by Mössbauer Spectroscopy after the upgrading experiment (Figure 5). As can be seen, a typical spectrum of the hematite $\left(\mathrm{Fe}_{2} \mathrm{O}_{3}\right)$ is found, which confirmed the presence of such phase on the surface of the $\mathrm{Fe}-20 / \mathrm{SiO}_{2}$ catalyst after the upgrading experiment $\left(315^{\circ} \mathrm{C}, 24 \mathrm{~h}\right)$.

Finally, to verify the presence of a carbonaceous phase found by XPS and XRD, a TGA analysis was carried out and an average of $2.8 \% \mathrm{w} / \mathrm{w}$ of loss in mass was observed after heating the used catalyst in oxygen atmosphere at $325{ }^{\circ} \mathrm{C}$ for $4 \mathrm{~h}$. Similar behavior was observed with the $\mathrm{Fe}-60 / \mathrm{SiO}_{2}$ catalyst. These results indicate that not only the catalysts were deactivating by particle sintering, but also by carbon deposition.

\subsection{Mechanistic Considerations}

In order to gain mechanistic information for the upgrading reactions, ${ }^{1} \mathrm{H}-\mathrm{NMR}$ analyes were carried out on the upgraded crude oil and the results are shown in Table 3. For the products of the three ironsupported, nanocatalysts increases $(15.1-15.9 \%)$ in the amount of $\alpha$-hydrogen bonded to aromatic rings were observed in comparison to those observed for the control run (14.8\%) and for the crude oil $(14.7 \%)$.

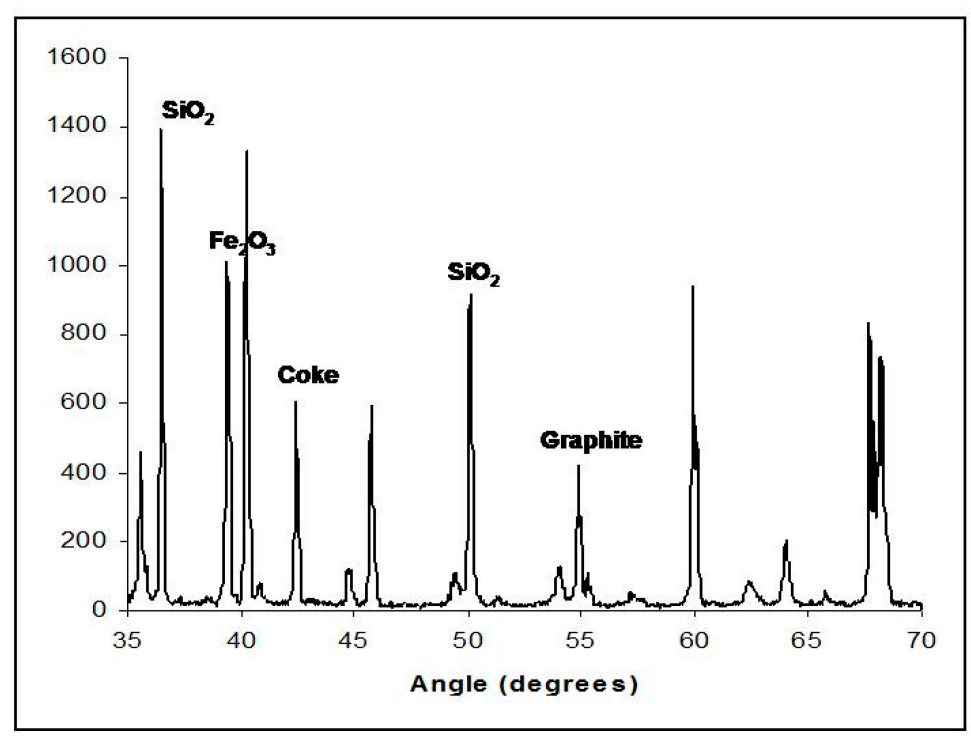

Figure 4. X-Ray Diffraction Analysis of the $\mathrm{Fe}-20 / \mathrm{SiO}_{2}$ catalyst after the upgrading reaction $\left(315^{\circ} \mathrm{C}\right.$ and $24 \mathrm{~h}$, tetralin). 


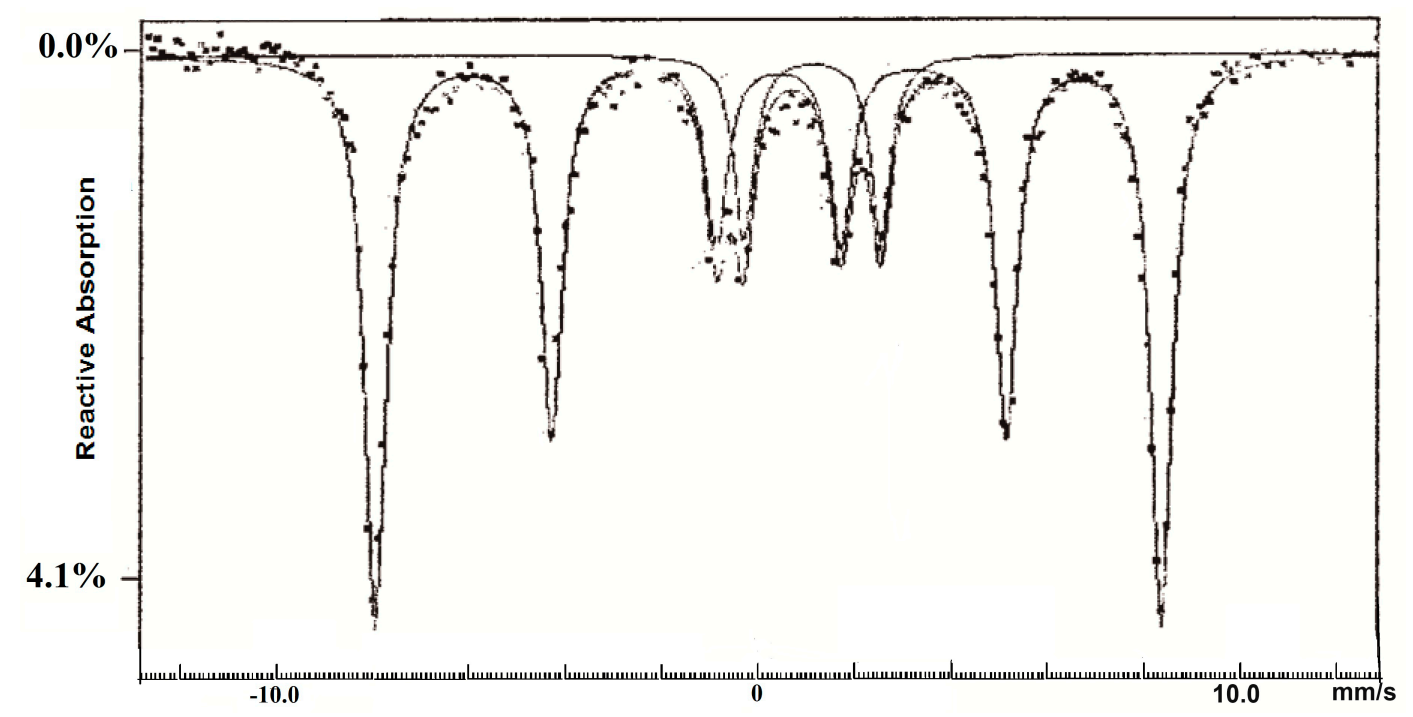

Figure 5. Mössbauer spectrum of $\mathrm{Fe}-20 / \mathrm{SiO}_{2}$ catalyst after the upgrading experiment $\left(315^{\circ} \mathrm{C}, 24 \mathrm{~h}\right)$ with the continuous line representing the result of a computer adjustment including, IS (Isomer Shift), FWHM and QS (quadrupole splitting).

Table 3. Protons distributions for upgraded Hamaca crude oils measured by ${ }^{1} \mathrm{H}$ NMR ${ }^{\mathrm{a}}$. Effect of the Presence of Iron Nanocatalysts.

\begin{tabular}{ccccccc}
\hline Run & Solid (Reaction time) & $\mathbf{H}_{\text {arom }}{ }^{\mathbf{b}}$ & $\mathbf{H}_{\text {aliph }}{ }^{\mathbf{c}}$ & $\mathbf{H}_{\boldsymbol{\alpha}}{ }^{\mathbf{d}}$ & $\mathbf{H}_{\boldsymbol{\beta}}{ }^{\mathbf{e}}$ & $\mathbf{H}_{\gamma}{ }^{\mathbf{}}$ \\
\hline- & Original Hamaca C. $^{\mathrm{e}}$ & 5.1 & 94.1 & 14.7 & 56.2 & 24.0 \\
1 & Control Exp.(0 h) $^{\mathrm{f}}$ & 5.6 & 94.4 & 14.8 & 55.2 & 24.4 \\
2 & Mineral Formation $^{\mathrm{g}}$ & 6.9 & 93.1 & 14.9 & 53.8 & 24.4 \\
3 & $\mathrm{Fe}-20 / \mathrm{SiO}_{2}{ }^{{ }^{\mathrm{h}}}$ & 7.6 & 92.4 & 15.4 & 52.1 & 24.9 \\
4 & $\mathrm{Fe}-60 / \mathrm{SiO}_{2}{ }^{\mathrm{h}}$ & 7.4 & 92.6 & 15.1 & 52.9 & 24.6 \\
5 & $\mathrm{Fe}-90 / \mathrm{SiO}_{2}{ }^{\mathrm{h}}$ & 6.8 & 93.2 & 14.9 & 54.0 & 24.3 \\
\hline
\end{tabular}

a The reactions were carried out as described in Table 1. Errors are expressed in terms of the standard deviations $( \pm 0.2 \%)$. ${ }^{b} \mathrm{H}_{\text {arom}}$ : percentages of hydrogen bonded to aromatic carbons. ${ }^{\mathrm{c}} \mathrm{H}_{\text {aliph }}$ : percentages of hydrogen bonded to aliphatic carbons. ${ }^{\mathrm{d}} \mathrm{H}_{\boldsymbol{\alpha}}$ : percentages of hydrogen bonded to aliphatic carbons in $\alpha$ position to an aromatic ring. ${ }^{\mathrm{e}} \mathrm{H}_{\beta}$ : percentages of hydrogen bonded to aliphatic carbons in $\beta$ position to an aromatic ring. ${ }^{\mathrm{f}} \mathrm{H}_{\gamma}$ : percentages of hydrogen bonded to aliphatic carbons in $\gamma$ or more position to an aromatic ring. ${ }^{\mathrm{f}}$ Same experimental conditions but the tetralin was removed and the products analyzed just as the reactor reached the operating temperature. ${ }^{\mathrm{g}}$ Natural mineral formation from the Hamaca reservoir. ${ }^{\mathrm{h}} 5 \% \mathrm{wt}$. (nominal) $\mathrm{Fe}$ supported on natural silica $\left(99 \% \mathrm{SiO}_{2}\right.$, partially dehydroxylated at $600{ }^{\circ} \mathrm{C}$ with a surface area of $\left.10 \mathrm{~m}^{2} / \mathrm{g}\right)$.

Furthermore, increases in aromatization occurred for all the upgrading reactions as shown by the increase in the percentages of aromatic protons from $5.1 \%$ in the original crude to $6.8-7.6 \%$ for runs 3-5. One plausible explanation could be metal catalyzed incorporation of the methyl groups to the crude oil molecules followed by thermal or catalytic aromatization of the naphthenic compounds, as shown in Equation (1) [22].

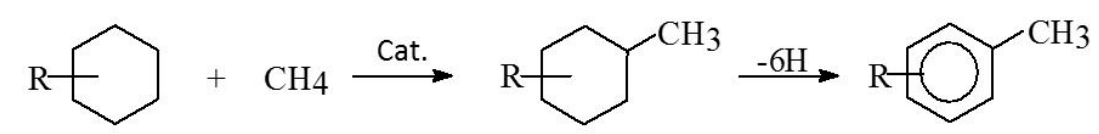


Egiebor and Gray found methyl- and dimethyl-substituted products by GC analysis of the donor solvent (tetralin), which was attributed to direct alkylation by reaction with methane during iron catalyzed coal liquefaction [23]. Also, similar results were obtained previously for extra-heavy crude oil upgrading under higher temperature $\left(380-420{ }^{\circ} \mathrm{C}\right)$ thermal [24] and catalytic conditions (Mo-containing catalyst) [22]. The incorporation of methyl groups, coming from methane, into the crude oil molecules was confirmed by isotopic carbon distribution measurements $\left({ }^{13} \mathrm{C} /{ }^{12} \mathrm{C}\right)$ using ${ }^{13} \mathrm{CH}_{4}$ as a source of hydrogen [22]. However, the addition of methane during the upgrading reaction is very small estimated value $(0.01 \% \mathrm{w} / \mathrm{w})$ and alternative explanations can be suggested as well. [22].

Additionally, an alternative explanation for the changes in protons distribution can be suggested. Depending on the substituents on cycloalkyl rings in the original oil, conversion of a naphthenic aromatic compounds such as 1-methyl-1,2,3,4-tetrahydronaphthalene to the corresponding aromatic analog (1-methyl naphthalene) leads to increases in both the percentages of aromatic protons and $\alpha$-hydrogen bonded to aromatic rings. Also, this type of reaction reduces $\beta$-hydrogen bonded to aromatics as observed in Table 3 .

The higher percentages of HDS obtained from the three iron supported nanocatalysts in comparison with the control and sand experiments (runs 1 and 2, Table 1) can also be explained by the generation of hydrogen as shown in Equation (1). Other alternate mechanisms can be proposed, such as a direct addition of methyl radicals to aromatic moieties. Further studies are required to address these important questions.

\section{Experimental Section}

The extra-heavy crude oil from the Orinoco Belt (Hamaca C.) used showed the following properties: $9.1^{\circ}$ API Gravity, 22.0\% asphaltenes (heptanes), 14.2\% Carbon Conradson, viscosity $\left(80{ }^{\circ} \mathrm{C}\right)=1810 \mathrm{cP}, 500{ }^{\circ} \mathrm{C}+$ residue $=71 \%, 7500 \mathrm{ppm}$ nitrogen, $3.75 \%$ sulfur, $450 \mathrm{ppm}$ of vanadium and $102 \mathrm{ppm}$ of nickel and initial boiling point of $201{ }^{\circ} \mathrm{C}$ at $\left.1 \mathrm{~atm}\right)$.

The iron catalysts were prepared by dispersing commercial nanoparticles $\mathrm{Fe}_{2} \mathrm{O}_{3}$ in methanol and mixing the resulting solution under inert atmosphere with naturally occurring sand from Yaracuy State, Venezuela $\left(99 \% \mathrm{SiO}_{2}\right.$, partially dehydroxylated at $600{ }^{\circ} \mathrm{C}$ with a superficial area of $\left.10 \mathrm{~m}^{2} / \mathrm{g}\right)$. After stirring for four $\mathrm{h}$, the methanol was removed at $50{ }^{\circ} \mathrm{C}$ under vacuum, and the percentage of iron was 5 wt.\% (nominal) for all the catalysts studied. The $20 \mathrm{~nm}\left(\mathrm{Fe}-20 / \mathrm{SiO}_{2}\right)$ and $60 \mathrm{~nm}\left(\mathrm{Fe}-60 / \mathrm{SiO}_{2}\right) \mathrm{Fe}_{2} \mathrm{O}_{3}$ nanoparticles (nominal) were purchased from Nantek and the $90 \mathrm{~nm}\left(\mathrm{Fe}-90 / \mathrm{SiO}_{2}\right)$ analog from Fildrech Science.

The upgrading reaction system as well as the experimental procedure are described elsewhere ${ }^{5}$. In a typical experiment, the reactor was loaded with extra-heavy crude oil sands (with or without the nanocatalyst and $10 \% w / w$ of crude oil), water, and tetralin (Aldrich used as received) at a weight ratio of 10:1:1, respectively. In all the experiments, the catalyst:crude oil ratio was 2:1.The reactor was heated at $5{ }^{\circ} \mathrm{C} / \mathrm{min}$ to $260-280{ }^{\circ} \mathrm{C}$, generating a final pressure of approximately 1600 psi for $24 \mathrm{~h}$ (900 psi initial methane pressure). After completing the experiment, water and tetralin were separated from the oil sands by vacuum distillation at $300^{\circ} \mathrm{C}$ and residual tetralin was less than $0.05 \%$ as revealed by H-NMR of the distillated residue. The reactor was then cooled to room temperature and oil was removed from sand by solvent extraction with dichloromethane. Crude oil and water mass balances were in the $93-99 \% w / w$ range with gas yields lower than $5 \% w / w$. Coke yields were below 
the detection limit of our technique $(1 \% \mathrm{w} / \mathrm{w})$. Percentages of recovery of tetralin were in the $92-105 \%$ range due to distillation of light fractions from the upgraded crude oils. All upgrading results are the average of at least two determinations.

Due to the small volume of samples analyzed, the percentages of sulfur removal (\%HDS) and of asphaltene reduction (Table 1) were calculated using Equations 2 and 3:

$$
\% \text { HDS }=\frac{(\text { Sulfur in original crude oil, wt } \%-\text { Sulfur in upgraded crude oil, wt } \%)}{(\text { Sulfur in original crude oil, wt } \%)}
$$

$$
\begin{aligned}
& \text { Percent of Asphaltene Reduction } \\
& =\frac{(\text { Asphaltenes in original crude oil, wt } \%-\text { Asphaltenes in upgraded crude oil, wt } \%)}{\text { (Asphaltenes in original crude oil, wt } \%)}
\end{aligned}
$$

Scanning electron microscopy (SEM) analyzes were carried out in an ISI equipment model SS-40 coupled with an EDAX X-ray analyzer model 9100. The particle sizes were the average of 100 measurements. The samples were covered with gold to improve contrast. X-Ray Photoelectron Spectroscopic (XPS) experiments were carried out using a Leybold-Heraeus Surface Analysis System, which was operated with an aluminum anode $(1486.6 \mathrm{eV})$. Pass energy was set at a constant value of $50 \mathrm{eV}$. The instrument sensitivity factors used for scaling the photoelectron peak areas were calculated using the method reported by Leon and Carrazza [25]. The Mössbauer spectroscopy was carried out at room temperature, with a constant acceleration spectrometer (Wissel), in the triangular symmetric mode for the velocity. The source was a ${ }^{57} \mathrm{Co}$ in Rhodium with a nuclear electronic acquisition system made by Oxford Tennelec.

\section{Conclusions}

Orinoco Belt crude oil (Hamaca C) can be upgraded (increases up to $8^{\circ}$ API, 26\% HDS, $27 \%$ reduction in the asphaltene content, etc.) in the presence of hydrogen donors (tetralin) and silica supported iron nanocatalysts under steam injection conditions $\left(280-315^{\circ} \mathrm{C}\right.$ and $\left.1600 \mathrm{psi}\right)$.

The characterization of the catalysts by TEM, XPS, EDAX, and Mössbauer spectroscopy before and after the upgrading reactions indicates the presence of hematite $\left(\mathrm{Fe}_{2} \mathrm{O}_{3}\right)$ as the most probable active species. The results indicated that the catalysts were deactivating by particle sintering $(\sim 20 \%$ increase in particle size), but also by carbon deposition.

For three iron-supported nanocatalysts, increases in the amount of $\alpha$-hydrogen bonded to aromatic rings were observed. Furthermore, increases in aromatization occurred for all the upgrading reactions as shown by the increase in the percentages of aromatic protons.

\section{Acknowledgments}

To the late Fernando Gonzalez, for their technical assistant for the Mossbauer experiments and for all the things he taught us. 


\section{Author Contributions}

Cesar Ovalles contributed to the experimental design and the article writing and revising. Victor Rivero and Arelys Salazar contributed to the catalyst characterization and evaluation.

\section{Conflicts of Interest}

The authors declare no conflict of interest

\section{References}

1. Weisman, J.G.; Kessler, R.V. Downhole heavy crude oil hydroprocessing. Appl. Catal. 1996, 140, $1-16$ and references therein.

2. Weissman, J.G.; Kessler, R.V.; Sawicki, R.A.; Belgrave, J.D.M.; Laureshen, C.J.; Metha, S.A.; Moore, R.G.; Ursenbach, M.G. Down-Hole Catalytic Upgrading of Heavy Crude Oil. Energy Fuels 1996, 10, 883-889 and references therein.

3. Vallejos, C.; Vasquez, T.; Ovalles, C. Process for the downhole upgrading of extra heavy crude oil. U.S. Patent 5,891,829, April 1999.

4. Ovalles, C.; Vallejos, C.; Vásquez, T.; Martinis, J.; Peréz-Peréz, A.; Cotte, E.; Castellanos, L.; Rodríguez, H. Extra-Heavy Crude Oil Downhole Upgrading Process using Hydrogen Donors under Steam Injection Conditions. In Proceedings of SPE International Thermal Operations and Heavy Oil Symposium, Margarita, Venezuela, 12-14 March 2001.

5. Ovalles, C.; Vallejos, C.; Vasquez, T.; Rojas, I.; Ehrman, U.; Benitez, J.L.; Martinez, R. Downhole Upgrading of Extra-Heavy Crude Oil Using Hydrogen Donor and Methane under Steam Injection Conditions. J. Pet. Sci. Tech. 2003, 21, 255-274.

6. Ovalles, C.; Rengel-Unda, P.; Bruzual, J.; Salazar A. Upgrading of Extra-Heavy Crude Using Hydrogen Donor under Steam Injection Conditions. Characterization by Pyrolysis GC-MS of the Asphaltenes and Effects of a Radical Initiator. Am. Chem. Soc. Div. Fuel. Chem. 2003, 48, $59-60$.

7. Hyne, J.B.; Clark, P.D.; Clarke, R.A.; Koo, J.; Greidanus, J.W.; Tyrer, J.D.; Verona, D. Aquathermolysis of Heavy Oils. Rev. Tech. INTEVEP 1982, 2, 87-94.

8. Viloria, A.; Parisi, S.; Martinez, E.; Gineika, A.; Sanchez, V. Efectos de la inyección de vapor sobre la calidad de un crudo extrapesado de la F.P.O. Rev. Tech. INTEVEP 1985, 5, 69-72.

9. Siskin, M.; Brons, G.; Katritzky, A.R.; Balasubramanian, M. Aqueous Organic Chemistry. 1. Aquathermolysis: Comparison with Thermolysis in the Reactivity of Aliphatic Compounds. Energy Fuels 1990, 4, 475-482 and references therein.

10. Rivas, O.R.; Campos, R.E.; Borges, L.G. Experimental Evaluation of Transition Metal Solutions as Additives in Steam Recovery Processes. Presented at 63th Annual Symposium of SPE, Houston, TX, USA, 2-5 October 1988.

11. Reynolds, J.G.; Thorsness, C.B. Mild Upgrading of Midway Sunset Crude Oil from The San Joaquin Valley of California by Aqueous Pyrolysis-Catalysis and Modeling. Presented at 213th ACS National Meeting, San Francisco, CA, USA, 13-17 April 1997. 
12. Nares, H.R.; Schacht-Hernandez, P.; Ramirez-Garnica, M.A.; Cabrera-Reyes, M.C.; Noe-Valencia, L. Heavy-Crude-Oil Upgrading with transition Metals. Presented at the SPE Latin America and Caribbean Petroleum Engineering Conference, Buenos Aires, Argentina, 15-18 April 2007.

13. Maity, S.K.; Ancheyta, J.; Marroquin, G. Catalytic Aquathermolysis Used for Viscosity Reduction of Heavy Oils: A Review. Energy Fuels 2010, 24, 2809.

14. Fumoto, E.; Sato, S.; Takanohashi, T. Oxidative Cracking of Oil Sand Bitumen with Iron Oxide Catalyst in a Steam Atmosphere. In Proceedings of 11th International Conference of Petroleum Phase behavior and Fouling, Petrophase. Jersey, NJ, USA, 13-17 June 2010.

15. Wang, Y.; Chen, Y.; He, J.; Li, P.; Yang, C. Viscosity Reduction of Heavy Oil through Catalytic Aquathermolysis at relatively Low Temperature. Presented at 11th International Conference of Petroleum Phase behavior and Fouling, Petrophase, Jersey, NJ, USA, 13-17 June 2010.

16. Wen, S.; Zhao, Y.; Liu, Y. A Study on Catalytic Aquathermolysis of Heavfy Crude Oil during steam Stimulation. Presented at 2007 SPE International Symposium Oilfield Chemistry, Houston, TX, USA, 28 February-2 March 2007.

17. Chen, Y.; Wang, Y.; Wu, C.; Xia, F. Laboratory Experiments and Field Tests of an Amphiphilic Metallic Chelate for Catalytic Aquathermolysis of Heavy Oil. Energy Fuels 2008, 22, 1502-1508.

18. Chao, K.; Chen, Y.; Liu, H.; Zhang, X.; Li J. Laboratory Experiments and Field Test of a Difunctional Catalyst for Catalytic Aquathermolysis of Heavy Oil. Energy Fuels 2012, 26, 1152-1159.

19. Chao, K.; Chen, Y.; Liu, H.; Zhang, X.; Li, J. Influences on the Aquathermolysis of Heavy Oil Catalyzed by Two Different Catalytic Ions: $\mathrm{Cu}^{2+}$ and $\mathrm{Fe}^{3+}$. Energy Fuels 2013, 27, 2555-2562.

20. Sakanishi, K.; Taniguchi, H.; Hasuo, H.-U.; Mochida, I. Iron-Based Catalysts Supported on Carbon Nanoparticles of Hollow Structure for Coal Liquefaction. Eng. Chem. Res. 1997, 36, 306309 and references therein.

21. Wagner, C.D.; Riggs, W.M.; Davis, L.E.; Moulder, J.F.; Muilenberg, G.E. Handbook of X-Ray Photoelectron Spectroscopy; Perkin-Elmer Corporation Physical Electronics Division: Eden Prairie, MN, USA, 1979.

22. Ovalles, C.; Filgueiras, E.; Morales, A.; Rojas, I.; de Jesus, J.C.; Berrios, I. Use of Dispersed Molybdenum Catalyst and Mechanistic Studies for Upgrading Extra-Heavy Crude Oil Using Methane as Source of Hydrogen. Energy Fuels 1998, 12, 379-385.

23. Egiebor, N.O.; Gray, M.R. Evidence for methane activation during coal pyrolysis and liquefaction. Fuel 1990, 69, 1276-1282.

24. Ovalles, C.; Hamana, A.; Rojas, I.; Bolivar, R. Upgrading of Extra-Heavy Crude Oil by Direct Use of Methane in the Presence of Water. Deuterium Labeled Experiments and Mechanistic Consideration. Fuel 1995, 74, 1162-1168.

25. Leon, V.; Carrazza, J. X- ray photoelectron spectroscopy (XPS) sensitivity factors. A general and simple approach. Rev. Tech. INTEVEP 1989, 9, 81-88.

(C) 2015 by the authors; licensee MDPI, Basel, Switzerland. This article is an open access article distributed under the terms and conditions of the Creative Commons Attribution license (http://creativecommons.org/licenses/by/4.0/). 